\title{
Genetic parameters of mid-infrared methane predictions and their relationships with milk production traits in Holstein cattle
}

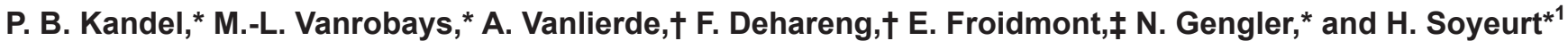 \\ *Department of AGROBIOCHEM and Terra Teaching and Research Centre, Gembloux Agro-Bio Tech, University of Liège, 5030 Gembloux, \\ Belgium \\ †Department of Valorisation of Agricultural Products, Agricultural Product Technology Unit, and \\ ‡Department of Production and Sectors, Animal Nutrition and Sustainability Unit, Walloon Agricultural Research Centre, 5030 Gembloux, Belgium
}

\begin{abstract}
Many countries have pledged to reduce greenhouse gases. In this context, the dairy sector is one of the identified sectors to adapt production circumstances to address socio-environmental constraints due to its large carbon footprint related to $\mathrm{CH}_{4}$ emission. This study aimed mainly to estimate (1) the genetic parameters of 2 milk mid-infrared-based $\mathrm{CH}_{4}$ proxies [predicted daily $\mathrm{CH}_{4}$ emission (PME, g/d), and log-transformed predicted $\mathrm{CH}_{4}$ intensity (LMI)] and (2) their genetic correlations with milk production traits [milk (MY), fat (FY), and protein (PY) yields] from first- and secondparity Holstein cows. A total of 336,126 and 231,400 mid-infrared $\mathrm{CH}_{4}$ phenotypes were collected from 56,957 and 34,992 first- and second-parity cows, respectively. The PME increased from the first to the second lactation (433 vs. $453 \mathrm{~g} / \mathrm{d}$ ) and the LMI decreased (2.93 vs. $2.86)$. We used 20 bivariate random regression test-day models to estimate the variance components. Moderate heritability values were observed for both $\mathrm{CH}_{4}$ traits, and those values decreased slightly from the first to the second lactation $(0.25 \pm 0.01$ and $0.22 \pm 0.01$ for PME; $0.18 \pm 0.01$ and $0.17 \pm 0.02$ for LMI). Lactation phenotypic and genetic correlations were negative between PME and MY in both first and second lactations ( -0.07 vs. -0.07 and -0.19 vs. -0.24 , respectively). More close scrutiny revealed that relative increase of PME was lower with high MY levels even reverting to decrease, and therefore explaining the negative correlations, indicating that higher producing cows could be a mitigation option for $\mathrm{CH}_{4}$ emission. The PME phenotypic correlations were almost equal to 0 with FY and PY for both lactations. However, the genetic correlations between PME and FY were slightly positive (0.11 and 0.12), whereas with PY the correlations were
\end{abstract}

Received September 2, 2016.

Accepted March 30, 2017.

${ }^{1}$ Corresponding author: hsoyeurt@ulg.ac.be slightly negative $(-0.05$ and -0.04$)$. Both phenotypic and genetic correlations between LMI and MY or PY or FY were always relatively highly negative (from -0.21 to -0.88$)$. As the genetic correlations between PME and LMI were strong ( 0.71 and 0.72 in first and second lactation), the selection of one trait would also strongly influence the other trait. However, in animal breeding context, PME, as a direct quantity $\mathrm{CH}_{4}$ proxy, would be preferred to LMI, which is a ratio trait of PME with a trait already in the index. The range of PME sire estimated breeding values were 22.1 and $29.41 \mathrm{~kg}$ per lactation in first and second parity, respectively. Further studies must be conducted to evaluate the effect of the introduction of PME in a selection index on the other traits already included in this index, such as, for instance, fertility or longevity.

Key words: dairy cow, methane, heritability, midinfrared, genetic correlation

\section{INTRODUCTION}

Due to its large carbon footprint, the dairy sector must to adapt its production circumstances to address the current socio-environmental constraints (Wollenberg et al., 2016). This environmental effect is mainly related to the emission of enteric $\mathrm{CH}_{4}$ by dairy cows occurring during the microbial fermentation of feed in rumen. Changes in feeding or adapted animal genetics are 2 relevant solutions to mitigate $\mathrm{CH}_{4}$ emission. Compared with feeding, genetic selection has a slower response on the field, but its effect is permanent and cumulative. To conduct successful genetic mitigation of $\mathrm{CH}_{4}, 3$ prerequisites are needed. First, $\mathrm{CH}_{4}$ traits must be sufficiently heritable from generation to generation to allow a relatively fast significant improvement. Second, a sufficient genetic variability of this studied trait must exist in the considered dairy cow population. Third, genetic correlations of $\mathrm{CH}_{4}$ with other traits of interest need to be known. To verify these 3 prerequisites, genetic analysis must be performed. 
Currently, more and more research focuses on the genetic variability of $\mathrm{CH}_{4}$ emitted by dairy cows. Heritability of $\mathrm{CH}_{4}$ emission quantified using respiration chambers, considered as the gold standard for $\mathrm{CH}_{4}$ measurements, is not available due to the technical and financial difficulties of obtaining sufficient phenotypes. However, few studies report heritability values using the gas analyzer technique. Pickering et al. (2015) found a heritability of 0.05 for the daily $\mathrm{CH}_{4}$ emission. For the same trait, Lassen and Løvendahl (2016) reported higher values (0.25). All of these results came from relatively low-scale studies (i.e., low number of cows and herds). To increase the number of phenotypes, the use of $\mathrm{CH}_{4}$ correlated traits that are more easily collected in the field and in many herds is relevant. Due to the high relationship between the quantity of $\mathrm{CH}_{4}$ eructed by dairy cows and feed intake, some authors estimated the heritability of $\mathrm{CH}_{4}$ from feed-intake-based $\mathrm{CH}_{4}$ predictions. So, Pickering et al. (2015) found a higher heritability compared with the one obtained from a gas analyzer (0.13). Cassandro et al. (2010) reported a similar heritability value (0.10). However, de Haas et al. (2011) estimated a higher heritability value (0.35). Even if this methodology allows the collection of a higher number of phenotypes, the acquisition of feed intake and composition records is not largely generalized on a routine basis.

Another alternative is the use of milk composition as a proxy of $\mathrm{CH}_{4}$ emission. The fatty acid (FA) profile seems to be valuable information (Chilliard et al., 2009; Dijkstra et al., 2011). So, van Engelen et al. (2015) estimated the heritability of $\mathrm{CH}_{4}$ yield $(\mathrm{g} / \mathrm{kg}$ of DMI) predicted from several groups of FA. The heritability obtained ranged from 0.12 to 0.44 . As the FA profile can be predicted using mid-infrared (MIR) spectrometry (Soyeurt et al., 2011), this method could be used to predict directly the quantity of $\mathrm{CH}_{4}$ eructed daily by dairy cows. So, Dehareng et al. (2012) developed the first MIR $\mathrm{CH}_{4}$ equation, which was later improved by Vanlierde et al. (2015, 2016). As this methodology is used currently for the milk recording, which implies an individual milk sample collection from all productive cows in all participating herds every 4 or 6 wk, the MIR $\mathrm{CH}_{4}$ phenotypes have the advantage of being fast and cheap, and allowing large-scale data recording. Moreover, as it is known that the quantity of $\mathrm{CH}_{4}$ eructed by dairy cows varies within and between lactations (Garnsworthy et al., 2012), the first objective of this study is the estimation of the genetic parameters of MIR $\mathrm{CH}_{4}$ emission (PME, g/d) and intensity (PMI, g/kg of milk) traits from first- and second-parity Holstein cows. Moreover, as the relationships of $\mathrm{CH}_{4}$ emission and intensity with other economically important traits are relatively unknown at a large scale, the second ob- jective of this paper was to estimate the phenotypic and genetic correlations between those $2 \mathrm{MIR} \mathrm{CH}_{4}$ traits with milk (MY), fat (FY), and protein (PY) yields.

\section{MATERIALS AND METHODS}

\section{Data}

Milk samples were collected from first- and secondparity Holstein cows between January 2010 and April 2014 as part of the routine milk recording undertaken in the Walloon region of Belgium by the Walloon Breeding Association (Ciney, Belgium). All milk samples were analyzed using Foss Milkoscan FT6000 spectrometers (Hillerød, Denmark) by the milk laboratory Comité du Lait (Battice, Belgium) to quantify the contents of fat and protein and to generate the spectral data.

The PME $(\mathrm{g} / \mathrm{d})$ was predicted from the recorded milk MIR spectra using the lactation-stage-dependent equation developed by Vanlierde et al. (2015). Briefly, this $\mathrm{CH}_{4}$ MIR prediction equation was developed from $446 \mathrm{CH}_{4}$ measurements from 142 Belgian and Irish cows. Reference daily $\mathrm{CH}_{4}$ emissions of individual cows were determined using the $\mathrm{SF}_{6}$ tracer gas technique with a gas collection period of $24 \mathrm{~h}$. The calibration data set was characterized by a mean of $416 \pm 128 \mathrm{~g}$ of $\mathrm{SF}_{6} \mathrm{CH}_{4} / \mathrm{d}$ with a minimum and maximum of 180 and $942 \mathrm{~g} / \mathrm{d}$. The lactation-stage-dependent equation was developed from those reference values and their corresponding daily milk MIR spectra. The standard error of calibration of this equation was $63 \mathrm{~g} / \mathrm{d}$. The calibration coefficient of determination was equal to $75 \%$. More details about the sample collection and data treatment are reported in Vanlierde et al., (2015). The PMI (g/ $\mathrm{kg}$ of milk) was defined as the ratio of PME divided by the daily MY $(\mathrm{kg} / \mathrm{d})$ recorded on the same test-day. This trait was then log-transformed to be normally distributed and called log-transformed $\mathrm{CH}_{4}$ intensity (LMI). To eliminate potential abnormal records, the predicted MIR $\mathrm{CH}_{4}$ trait values below the 0.1 percentile and above the 99.9 percentile were deleted.

Only cows between 5 and 365 DIM and with at least $75 \%$ Holstein genes were studied. If a cow had $\mathrm{CH}_{4}$ records for second parity, this cow must also have records for first parity to be considered in the study. As proposed by the International Committee for Animal Recording, milk production records were retained if they were between 3 and $99 \mathrm{~kg}$ of MY, 1 and $7 \%$ of PY, and 1.5 and $9 \%$ of FY. Moreover, only herds having at least $100 \mathrm{MIR} \mathrm{CH}_{4}$ phenotypes were kept in this study. Therefore, the final data set contained 366,126 and 231,400 test-day records collected from 56,957 and 34,992 first- and second-parity Holstein cows belonging to 935 herds. Pedigree data were obtained from the 
pedigree database used for the Walloon genetic evaluation. The pedigree file contained 120,504 animals born after 1990. The average number of daughters per sire was 84 with a minimum of 15 daughters and a maximum of 9,762 daughters from a total of 581 sires.

\section{Genetic Analyses}

Twenty bivariate random regression test-day models were performed to estimate the variance components of studied traits. The pairs were PME and MY; PME and FY; PME and PY; LMI and MY; LMI and FY; LMI and $\mathrm{PY} ; \mathrm{MY}$ and $\mathrm{FY} ; \mathrm{MY}$ and $\mathrm{PY} ; \mathrm{FY}$ and $\mathrm{PY}$; and PME and LMI in first and second lactation. The model can be summarized as follows:

$$
\mathbf{y}=\mathbf{X} \boldsymbol{\beta}+\mathbf{Q}(\mathbf{H h}+\mathbf{Z} \mathbf{p}+\mathbf{Z u})+\mathbf{e}
$$

where $\mathbf{y}$ was the vector of observations of a pair of 2 traits, $\boldsymbol{\beta}$ was the vector of fixed effects [herd $\times$ test-day, DIM (24 classes of a 15-d interval), and age at calving (3 classes for each lactation: 21 to $28 \mathrm{mo}, 29$ to $32 \mathrm{mo}$, and $33 \mathrm{mo}$ and more for first lactation and 31 to $44 \mathrm{mo}$, 44 to $48 \mathrm{mo}$, and $49 \mathrm{mo}$ and more for second lactation], $\mathbf{h}$ was the vector of random within-herd lactation curve effects, $\mathbf{p}$ was the vector of permanent environmental random effects, $\mathbf{u}$ was the vector of additive genetic random effects, $\mathbf{Q}$ was the matrix containing the coefficients of 2 nd order Legendre polynomials, e was the vector of residuals, $\mathbf{X}$ was the incidence matrix assigning observations to fixed effects, $\mathbf{H}$ was the incidence matrix assigning observations to random within-herd lactation curve effects, and $\mathbf{Z}$ was the incidence matrix assigning observations to the additive genetic or permanent environmental effects.

Variance components were estimated by Bayesian method using Gibbs sampling (Misztal, 2012). Priors of variance components were estimated from univariate models using average information REML method (Misztal, 2012). Posterior means of (co)variance components were calculated using 100,000 iterations after a burn-in of 10,000 iterations. As 3 replicates were available for the variance components for each studied trait due to the number of used bivariate models, the variance estimates were averaged.

Average daily heritability value was the average of heritability estimated for each DIM between 5 and 305 DIM. The daily heritability at a specific DIM was calculated as the ratio of the genetic variance to the total variance (i.e., the sum of variances estimated from the within-herd lactation curve, genetic variances, permanent environment, and residual) at the considered DIM. Standard errors of heritability estimates were computed using the method reported by Fischer et al. (2004) based on variance estimates from the inverse of the average information matrix.

Daily phenotypic and genetic correlations between trait $a$ and trait $b$ at DIM $i$ were calculated as follows:

$$
r_{a_{i}, b_{i}}=\frac{\mathbf{t} \sum_{a, b} \mathbf{t}^{\prime}}{\sqrt{\left(\mathbf{t}_{i} \sum_{a} \mathbf{t}_{i}^{\prime}\right) \cdot\left(\mathbf{t}_{i} \sum_{b} \mathbf{t}_{i}^{\prime}\right)}},
$$

where $\mathbf{t}$ was the vector created by summing coefficients of Legendre polynomials for DIM 5 to $305 ; \Sigma_{a, b}$ was the matrix including the genetic or phenotypic covariances between trait $a$ and trait $b$; and $\Sigma_{a}$ and $\Sigma_{b}$ were the genetic or phenotypic variance matrices for traits $a$ and $b$, respectively.

The breeding values were estimated (EBV) using a BLUP approach. Daily EBV for each DIM between 1 and 305 and for cows with records were calculated as follows:

$$
\text { daily } \mathrm{EBV}_{h t k}=\sum_{m=0}^{2} a_{h k m} z_{t m}
$$

where daily $\mathrm{EBV}_{h t k}$ was the daily breeding value of cow $k$, for trait $h$, for each DIM $t$ between 5 and $305 ; a_{h k m}$ was the BLUP solution of the additive genetic effect of order $m ; z_{t m}$ was the covariate of Legendre polynomial of order $m$ associated with DIM $t$; and $z_{t 0}=1.0, z_{t 1}=$ $3.0^{0.5} x, z_{t 2}=5.0^{0.5}\left(1.5 x^{2}-0.5\right)$, where $x=2[(t-5) / 305]$ - 1. Only EBV of sire having daughters with MIR $\mathrm{CH}_{4}$ phenotypes were kept for this step. All daily EBV were cumulated to get 305-d EBV of animal for each trait. The Spearman correlations were calculated between EBV of sires estimated using first- and second-parity records to assess the differences between sire rankings for all MIR $\mathrm{CH}_{4}$ traits.

\section{RESULTS}

\section{MIR $\mathrm{CH}_{4}$ Traits and Their Observed Relationships with Milk Yield}

Table 1 provides the mean and standard deviation of all studied traits in first and second lactation. The PME increased from the first to the second lactation (433 vs. $453 \mathrm{~g} / \mathrm{d}$ ). Inversely, PMI decreased (19.8 vs. $18.8 \mathrm{~g} / \mathrm{kg}$ of milk), as did LMI (2.93 vs. 2.86). The coefficients of variation between lactations stayed relatively stable for all studied $\mathrm{CH}_{4}$ traits (18.6 and $17.1 \%$ for PME; 11.1 and $12.8 \%$ for LMI in the first and second lactation, respectively). 
Table 1. Mean \pm SD of all studied traits

\begin{tabular}{|c|c|c|}
\hline Trait $^{1}$ & $\begin{array}{l}\text { Lactation } 1 \\
(\mathrm{n}=366,435)\end{array}$ & $\begin{array}{c}\text { Lactation } 2 \\
(\mathrm{n}=231,743)\end{array}$ \\
\hline MIR $\mathrm{CH}_{4}$ emission $(\mathrm{g} / \mathrm{d})$ & $433 \pm 80$ & $453 \pm 78$ \\
\hline MIR $\mathrm{CH}_{4}$ intensity (g/kg of milk) & $19.8 \pm 6.8$ & $18.8 \pm 7.6$ \\
\hline Log-transformed $\mathrm{MIR} \mathrm{CH}_{4}$ intensity & $2.93 \pm 0.33$ & $2.86 \pm 0.37$ \\
\hline Milk yield $(\mathrm{kg} / \mathrm{d})$ & $23.41 \pm 6.42$ & $26.79 \pm 8.24$ \\
\hline Fat yield $(\mathrm{kg} / \mathrm{d})$ & $0.92 \pm 0.23$ & $1.07 \pm 0.32$ \\
\hline Protein yield (kg/d) & $0.78 \pm 0.19$ & $0.90 \pm 0.25$ \\
\hline
\end{tabular}

Figure 1a illustrates the relationship between PME and MY. An increase of MY increased PME until on average $20 \mathrm{~kg}$ of milk/d; then the relationship was al- most flat and was slightly negative for cows with high daily productivity. The PME increased at the beginning of lactation, but in contrast to MY, the peak of PME

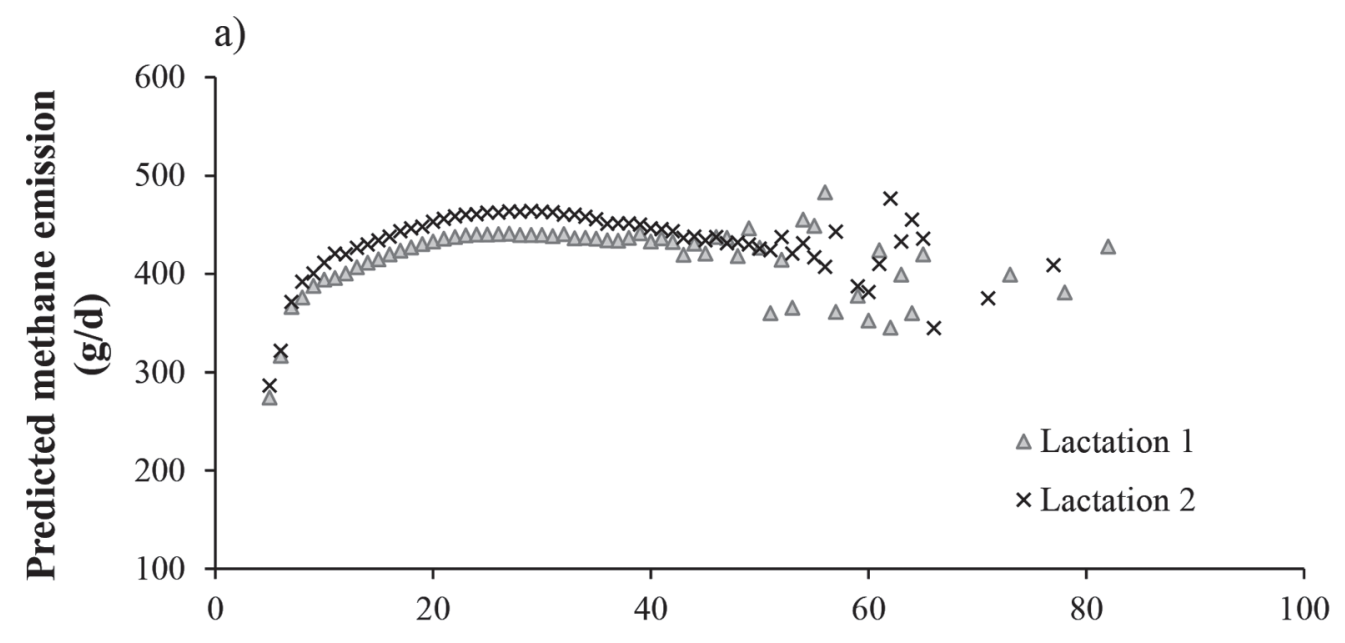

b)

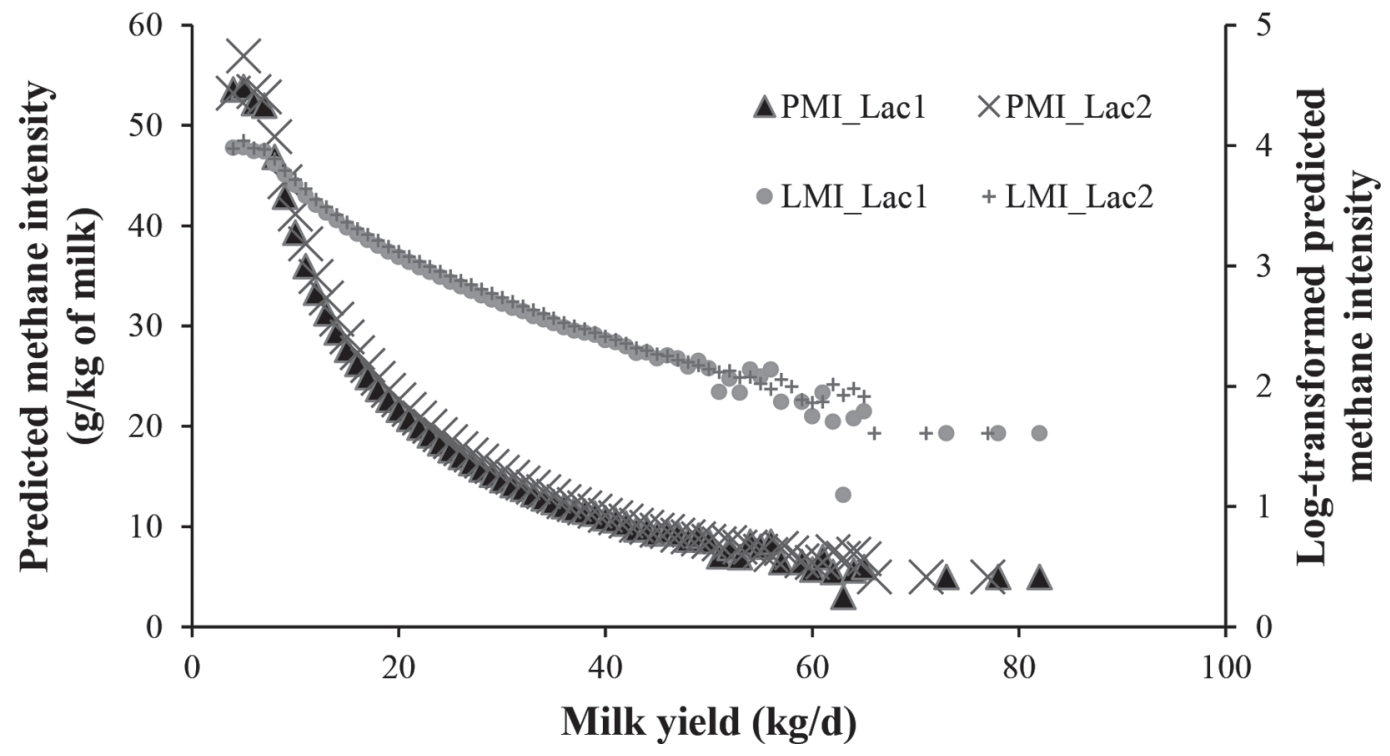

Figure 1. Relationship between mid-infrared predicted $\mathrm{CH}_{4}$ emission (g/d; a) or intensity [PMI; g/kg of milk, and $\log _{10}(\mathrm{PMI})$, called LMI; b] and milk yield (kg/d) from first- and second-parity Holstein cows. Lac1 = lactation 1; Lac2 = lactation 2. 
reached later (after 120th DIM; Figure 2a). Similar patterns were observed for both studied lactations even if the values were slightly higher for the second lactation (Figure 2a).

The relationship between MY and PMI was curvilinear, and after log-transformation, the relationship was linearized (Figure 1b). The LMI pattern within lactation was the lowest around 50th DIM and higher values at beginning and late lactation. Due to the higher MY in second lactation, PMI was lower throughout second lactation than first lactation (Figure 2b).

\section{Heritability Estimates of MIR $\mathrm{CH}_{4}$ Traits}

We have observed moderate heritability values for PME and those values decreased slightly between first and second lactation $(0.25 \pm 0.01$ and $0.22 \pm 0.01)$.
Lower values were observed for LMI compared with PME and stayed stable between lactations $(0.18 \pm$ 0.01 and $0.17 \pm 0.02$; Table 2). Values of heritability estimated for MY, FY, and PY were similar to those previously reported by Bastin et al. (2013) from Walloon Holstein cattle.

Within lactation, daily heritability of PME ranged from 0.20 to 0.27 in first lactation and from 0.16 to 0.26 in second lactation. In first lactation, heritability estimates of PME increased from the beginning, were higher in mid lactation, and decreased toward the end of lactation. In second lactation, PME heritability decreased from early lactation toward the end of lactation (Figure 3). Within lactation, LMI ranged from 0.12 to 0.24 and from 0.13 to 0.19 in first and second lactation, respectively. The heritability values of LMI in both lactations increased linearly from the beginning to the

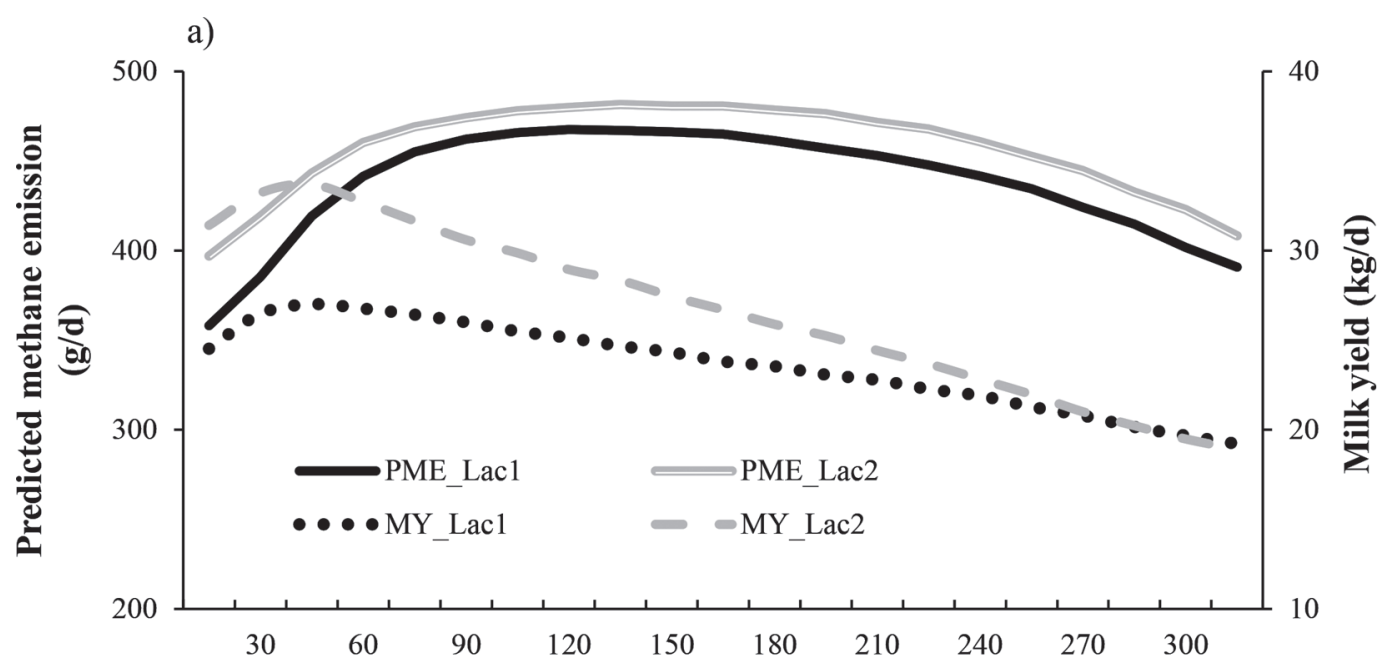

b)

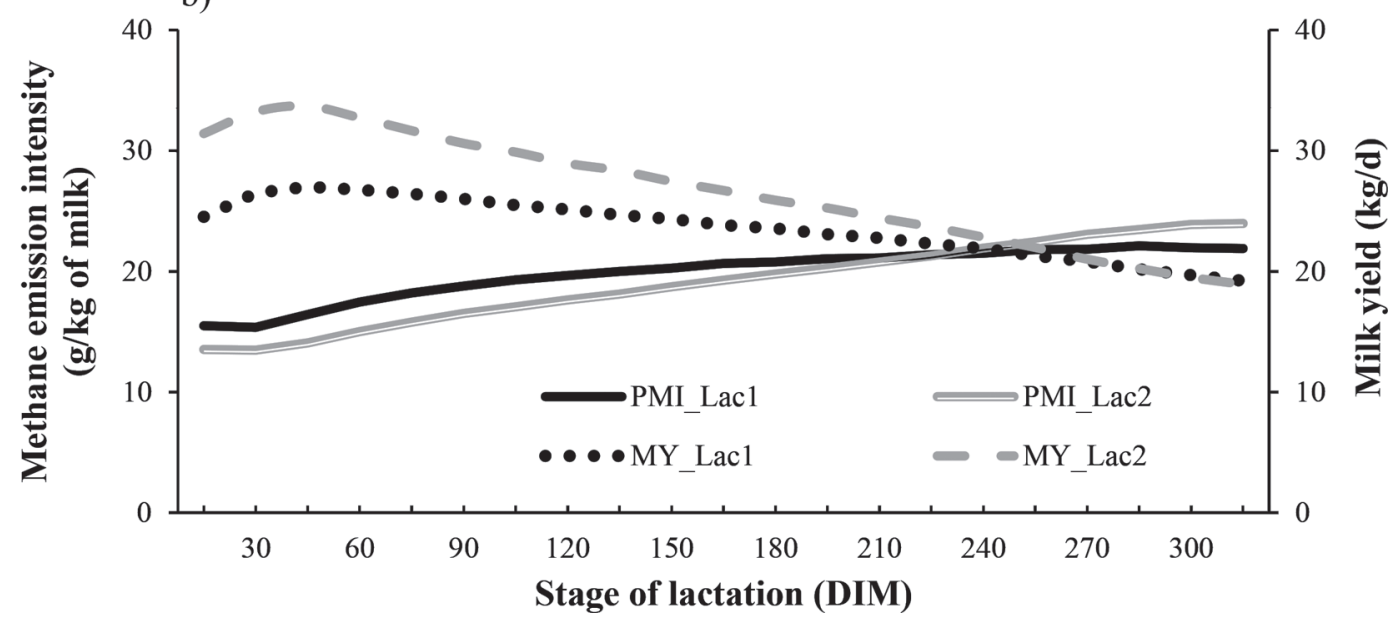

Figure 2. Change in daily mid-infrared (MIR) $\mathrm{CH}_{4}$ emission (PME), milk yield (MY), MIR $\mathrm{CH}_{4}$ intensity (PMI), and log 10 (PMI), called LMI, across lactation from first- and second-parity Holstein cows. Lac1 = lactation 1; Lac2 = lactation 2. 


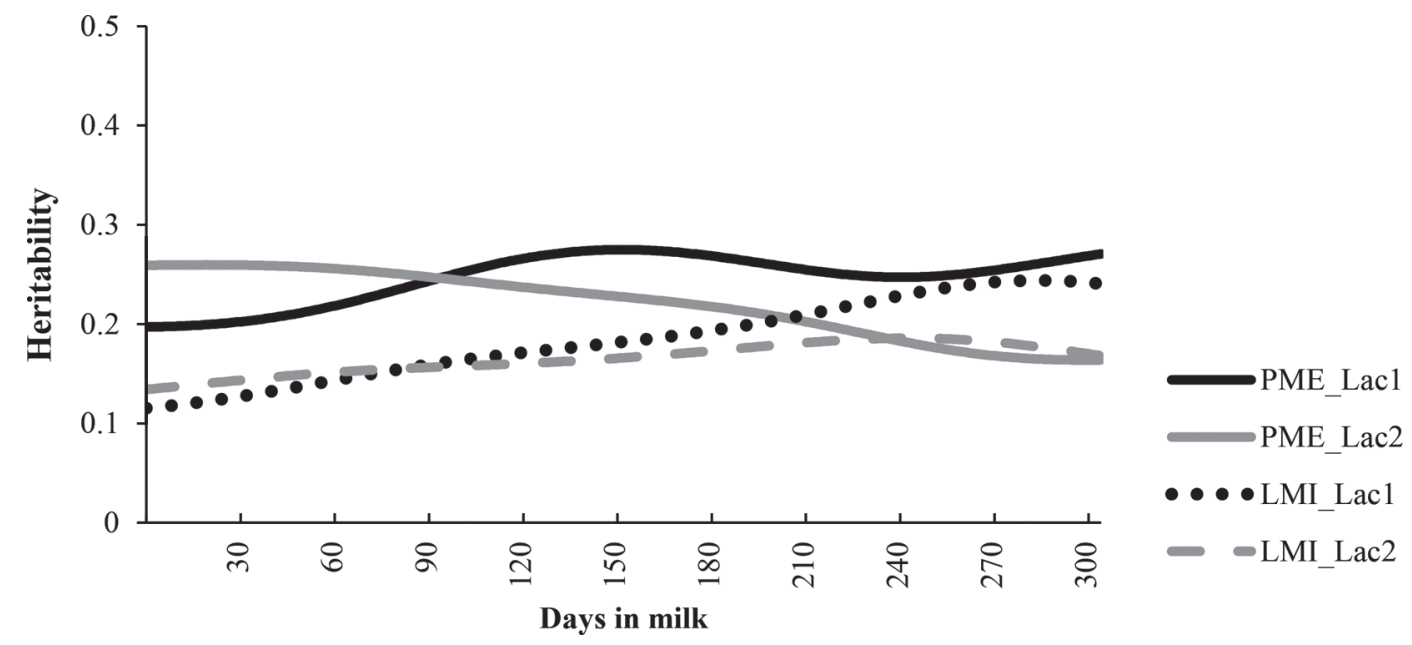

Figure 3. Daily heritability estimates for mid-infrared (MIR) $\mathrm{CH}_{4}$ emission (PME) and log-transformed predicted $\mathrm{MIR} \mathrm{CH}_{4}$ intensity (LMI) in first and second lactation. Lac1 = lactation 1; Lac2 = lactation 2.

end of lactation. The LMI heritability pattern observed for the 2 lactations was globally similar even if larger differences of heritability appeared at the end of the lactation (Figure 3).

\section{Phenotypic and Genetic Correlations Between MIR $\mathrm{CH}_{4}$ Traits and Milk Yield}

Phenotypic correlations between PME and MY were slightly negative in both lactations $(-0.07)$. The estimated within-lactation phenotypic correlations were equal to -0.11 at the beginning of lactations and then increased gradually toward zero until the end of lactation (Figure 4a). However, at the genetic level, the estimated correlations were higher. Indeed, the lactation genetic correlations were equal to -0.19 and -0.24 for the first and second lactation, respectively (Table 2 ). Compared with the phenotypic level, the changes of genetic correlations throughout the lactation were more marked for the first lactation. Indeed, the genetic correlations decreased until around 200 DIM and then increased rapidly until the end of lactation (Figure 4a).

Phenotypic correlations between LMI and MY were highly negative in both lactations $(-0.68$ and -0.72 ; Table 2) and stayed relatively constant throughout the lactation even if a slight decrease of values can be observed for the second parity at the end of the lactation (Figure 4b). Highly negative correlations were also observed at the genetic level. The values ranged between -0.60 and around -0.85 for both lactations. The correlations decreased until around 180 DIM and then increased until the end of lactation (Figure $4 \mathrm{~b}$ ).

\section{Phenotypic and Genetic Correlations Between MIR $\mathrm{CH}_{4}$ Traits and Fat Yield}

Lactation phenotypic correlations between PME and FY were almost equal to zero in both lactations ( -0.01 and 0.01 ; Table 2). However, marked changes of phenotypic correlations were observed throughout the

Table 2. Heritability (diagonal in bold), phenotypic (below the diagonal), and genetic (above the diagonal) correlations between mid-infrared (MIR) $\mathrm{CH}_{4}$ traits and production traits in first- (first row) and secondlactation (second row) Holstein cows

\begin{tabular}{lccccc}
\hline Item $^{1}$ & PME & LMI & Milk yield & Fat yield & Protein yield \\
\hline PME & $\mathbf{0 . 2 5}$ & 0.71 & -0.19 & 0.11 & -0.05 \\
& $\mathbf{0 . 2 2}$ & 0.72 & -0.24 & 0.12 & -0.04 \\
LMI & 0.47 & $\mathbf{0 . 1 8}$ & -0.68 & -0.21 & -0.66 \\
& 0.46 & $\mathbf{0 . 1 7}$ & -0.88 & -0.26 & -0.62 \\
Milk yield & -0.07 & -0.68 & $\mathbf{0 . 1 6}$ & 0.79 & 0.92 \\
& -0.07 & -0.72 & $\mathbf{0 . 1 4}$ & 0.84 & 0.94 \\
Fat yield & -0.01 & -0.43 & 0.79 & $\mathbf{0 . 1 3}$ & 0.82 \\
Protein yield & 0.01 & -0.51 & 0.83 & $\mathbf{0 . 1 2}$ & 0.86 \\
& -0.02 & -0.55 & 0.92 & 0.82 & $\mathbf{0 . 1 4}$ \\
\hline
\end{tabular}

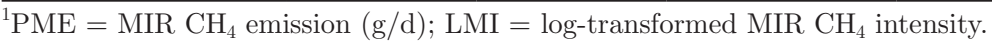


a)

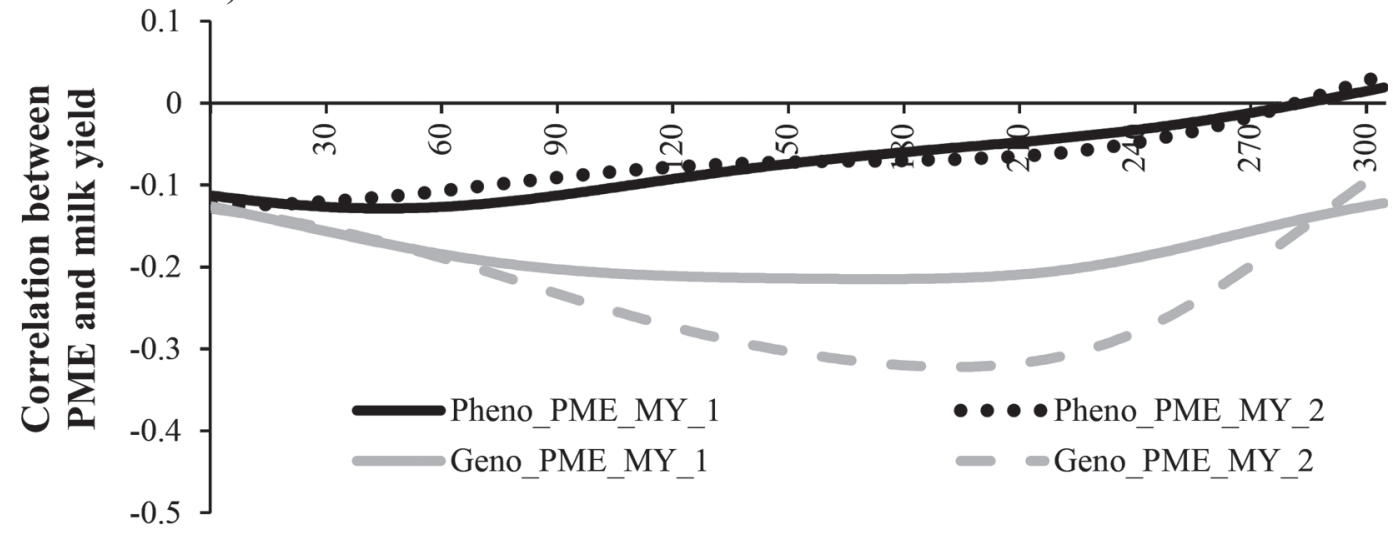

b)

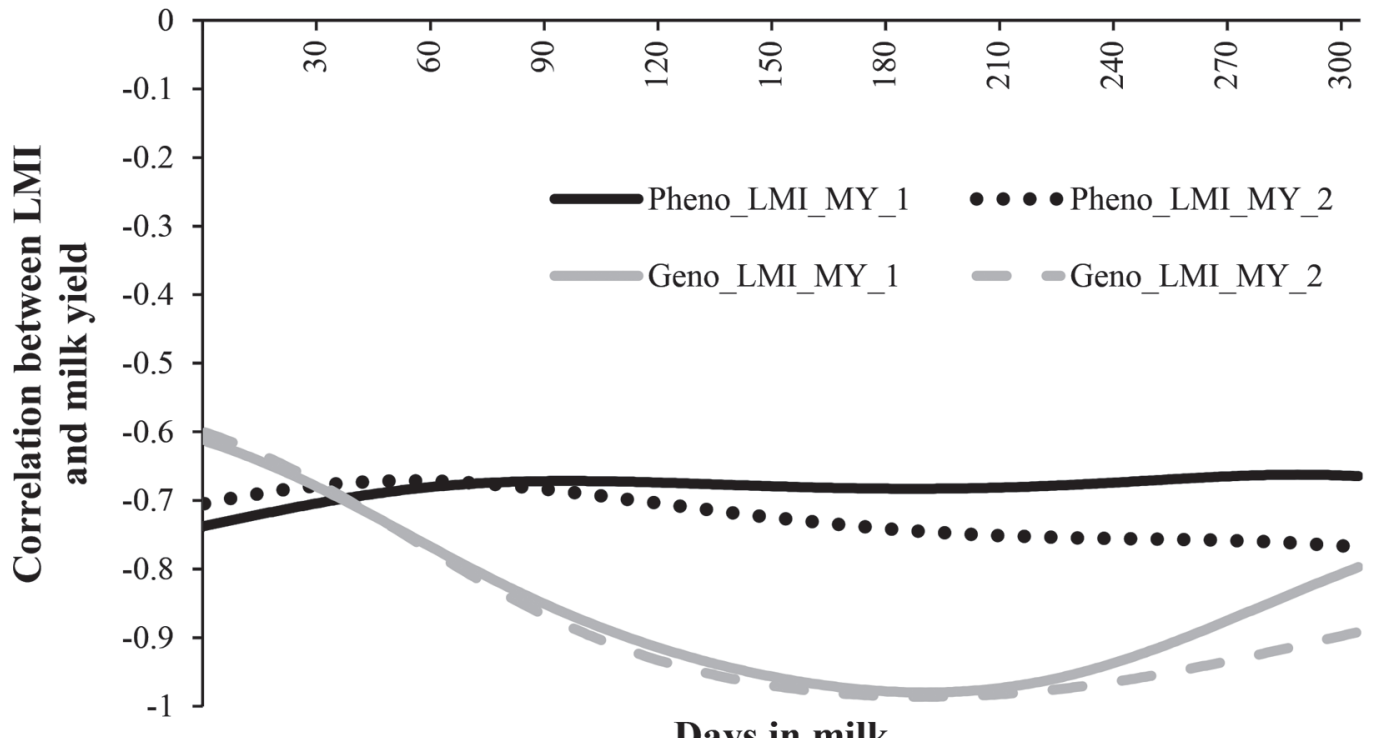

Days in milk

Figure 4. Genetic (Geno) and phenotypic (Pheno) correlations between mid-infrared (MIR) CH4 emission (PME; a) or log-transformed MIR CH4 intensity (LMI; b) and milk yield (MY) within the first (1) and second (2) lactation.

lactation. Indeed, the within lactation phenotypic correlations between PME and FY were negative at early lactation, zero at mid lactation, and positive at late lactation. We have observed this tendency in both studied lactations (Figure 5a). At the genetic level, lactation correlations were positively higher $(0.11$ and 0.12 ; Table 2); however, negative correlations were observed at the beginning of second lactation until 90 DIM. In the first lactation, the correlation values were globally positive throughout the lactation (Figure 5a).

Lactation phenotypic correlations between LMI and FY were moderately negative for both lactations $(-0.43$ and -0.51 ; Table 2). Compared with PME, the correlations values were always negative throughout the lactation (Figure 5b).

\section{Phenotypic and Genetic Correlations Between MIR $\mathrm{CH}_{4}$ Traits and Protein Yield}

As observed with FY, lactation phenotypic correlations estimated between PME and PY were almost equal to 0 in both lactations $(-0.02$ and 0.01 ; Table 2 ). Similarly to FY, the within lactation phenotypic correlations between PME and PY were negative at early lactation, zero at mid lactation, and positive at late lactation in both studied lactations (Figure 6a). Compared with FY, the genetic correlations estimated between PME and PY stayed relatively similar to the ones obtained at the phenotypic level $(-0.05$ and -0.04 ; Table 2). However, the pattern of genetic correlation changes was fluctuated more (Figure 6a). 
Lactation phenotypic correlations between LMI and PY were higher than the ones observed with FY but lower than the ones observed for MY $(-0.55$ and -0.61 ; Table 2). At the genetic level, the correlations were also negative and the values were similar to the ones observed at the phenotypic level $(-0.66$ and -0.62 ; Table 2). Within lactation correlations between LMI and PY were relatively stable at the phenotypic level but fluctuated more at the genetic level (Figure 6b).

\section{Genetic Variability of $\mathrm{CH}_{4}$ MIR Traits}

The EBV of MIR $\mathrm{CH}_{4}$ traits in both lactations were estimated for sires that had daughters with $\mathrm{MIR} \mathrm{CH}_{4}$ phenotypes. The lowest sire EBV for PME cumulated at $305 \mathrm{~d}$ was $-11.15 \mathrm{~kg}$ in the first lactation and -15.68 $\mathrm{kg}$ in the second lactation; the highest sire EBV for
PME cumulated at $305 \mathrm{~d}$ was $11.01 \mathrm{~kg}$ in the first lactation and $13.73 \mathrm{~kg}$ in the second lactation. The range was therefore equal to $22.15 \mathrm{~kg}$ in first parity and 29.41 $\mathrm{kg}$ in second parity. The Spearman correlations of EBV of PME between first and second lactation were 0.92 and 0.95 for LMI.

\section{DISCUSSION}

Current selective breeding objectives for dairy cattle do not include enteric $\mathrm{CH}_{4}$ traits. However, the improvement of livestock through genetics is particularly an effective technology, producing permanent and cumulative changes of trait in a desired direction (Wall et al., 2010). In this context, a study about the genetic variability of MIR $\mathrm{CH}_{4}$ predictions can be a starting point for the inclusion of such an environmental trait in

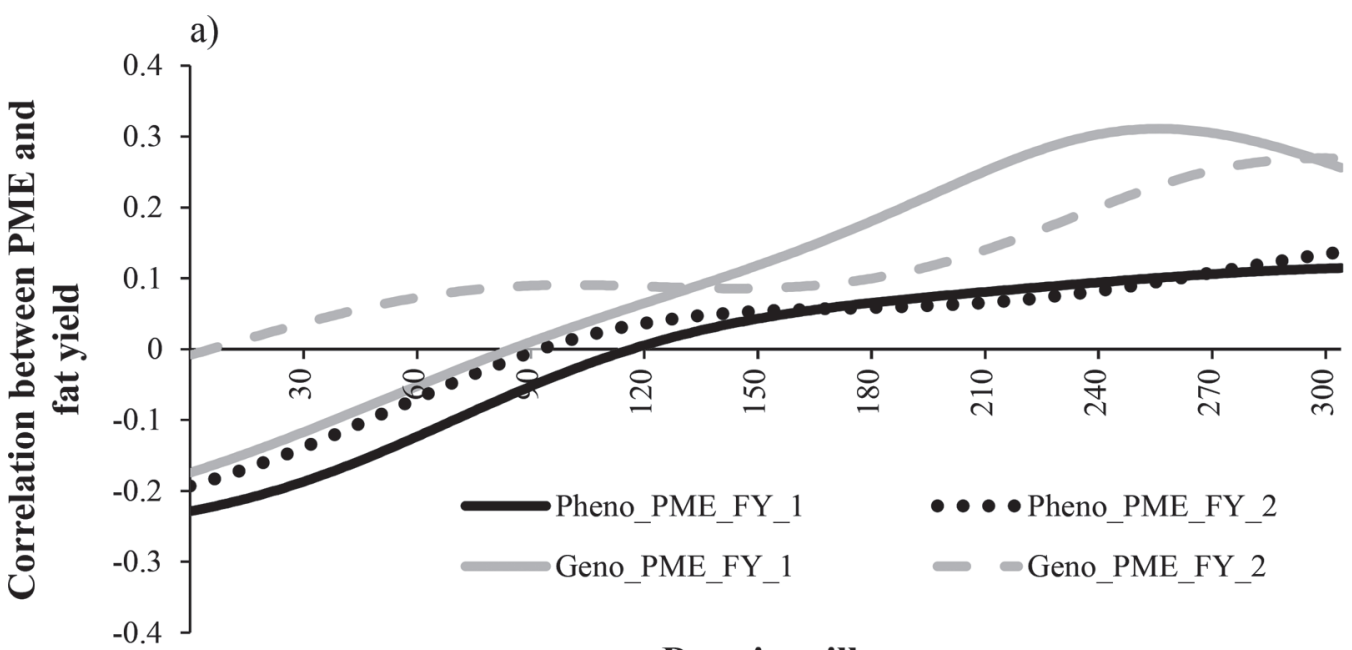

Days in milk

b)

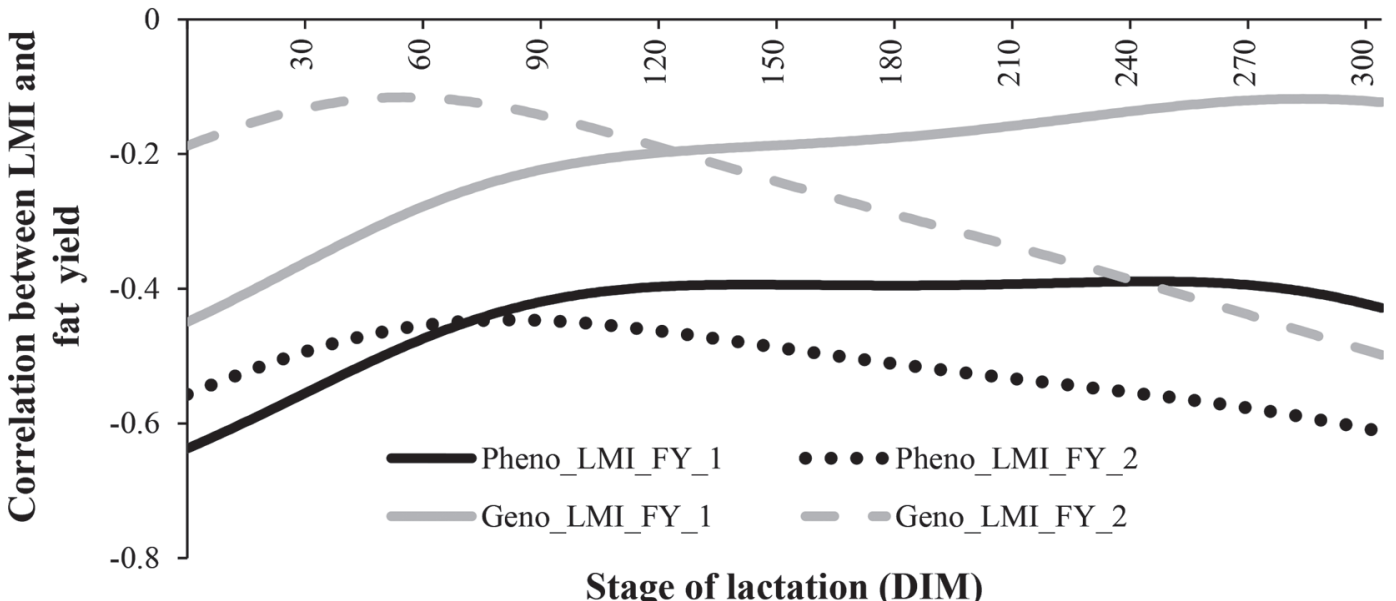

Figure 5. Genetic (Geno) and phenotypic (Pheno) correlations between mid-infrared (MIR) CH4 emission (PME; a) or log-transformed MIR CH4 intensity (LMI; b) and fat yield (FY) within the first (1) and second (2) lactation. 


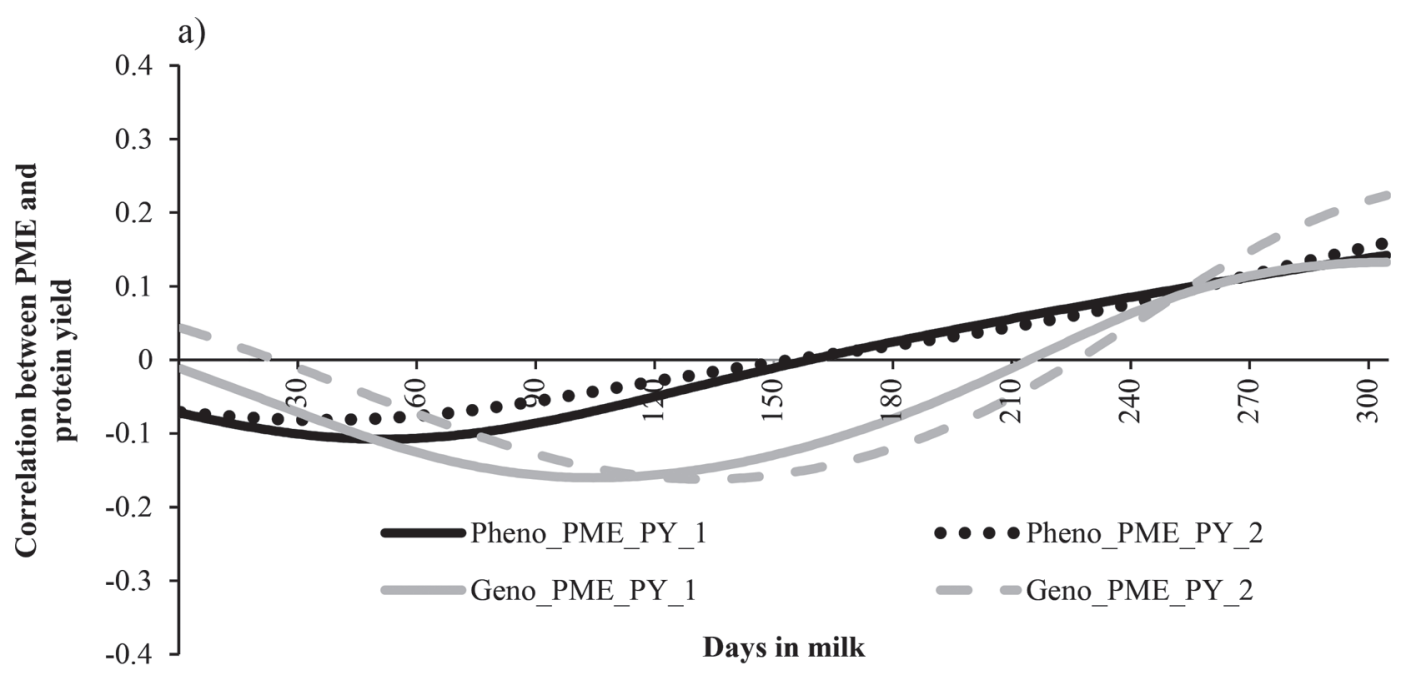

b)

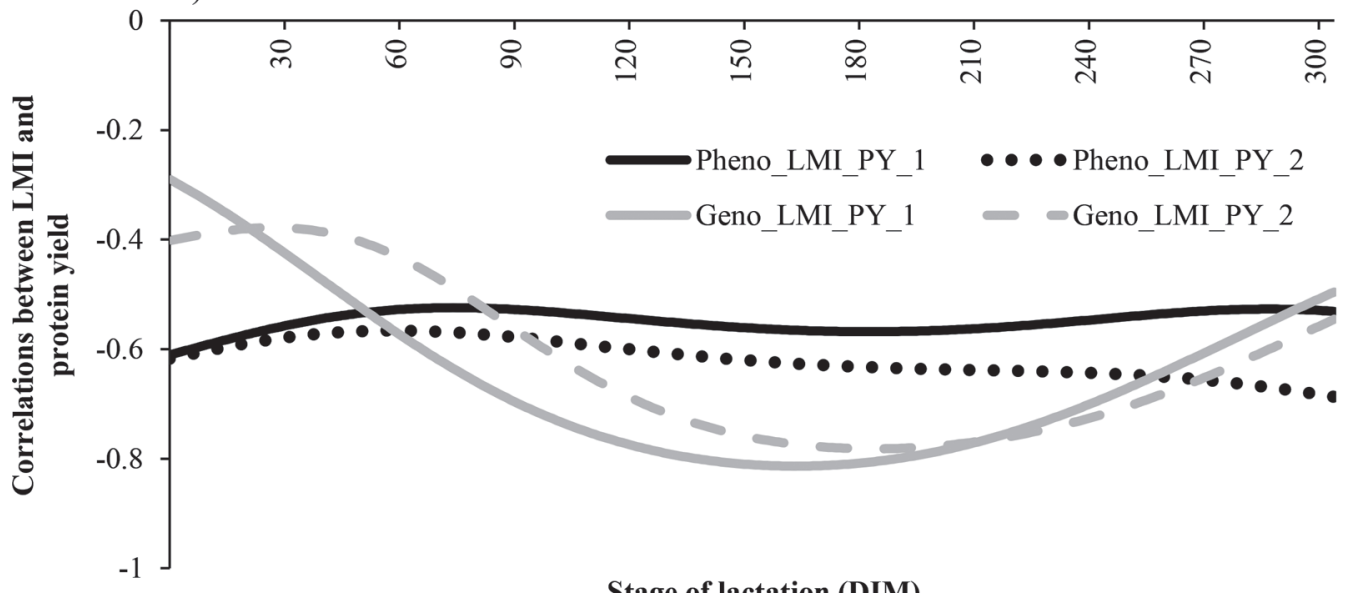

Stage of lactation (DIM)

Figure 6. Genetic (Geno) and phenotypic (Pheno) correlations between mid-infrared (MIR) CH4 emission (PME; a) or log-transformed MIR CH4 intensity (LMI; b) and protein yield (PY) within the first (1) and second (2) lactation.

a future selection index. To achieve this, 3 prerequisites must be verified: (1) MIR $\mathrm{CH}_{4}$ traits must have a behavior similar to the one observed from gold standard $\mathrm{CH}_{4}$ measurements, (2) MIR $\mathrm{CH}_{4}$ traits must be heritable, and (3) MIR $\mathrm{CH}_{4}$ traits must present a sufficient genetic variability in the studied dairy cow population. Finally, if all of these prerequisites are satisfied, the knowledge of the relationships between these MIR traits with high economic interest traits is required. We have considered only the relationships with milk production traits in this paper.

\section{Behavior of MIR $\mathrm{CH}_{4}$ Traits Compared with Reference $\mathrm{CH}_{4}$ Measurements}

This study used $\mathrm{CH}_{4}$ phenotypes predicted using milk MIR spectrometry. The calibration coefficient of deter- mination for the MIR $\mathrm{CH}_{4}$ equation used was equal to 0.75 and their calibration standard error was $63 \mathrm{~g} / \mathrm{d}$ (Vanlierde et al., 2015). Therefore, the phenotypes used in this study must be considered as a proxy for the enteric quantity of $\mathrm{CH}_{4}$ eructed by dairy cows. So, it is necessary to verify if these $\mathrm{MIR} \mathrm{CH}_{4}$ phenotypes have the expected behavior compared with the findings published in the literature.

The means of PME (433 and $453 \mathrm{~g} / \mathrm{d}$ ) and PMI (19.8 and $18.8 \mathrm{~g} / \mathrm{kg}$ of milk; Table 1 ) were within the range reported in several studies conducted on dairy cows. For instance, Veneman et al. (2015) reported $430 \mathrm{~g}$ of $\mathrm{CH}_{4} / \mathrm{d}$ and $21.4 \mathrm{~g}$ of $\mathrm{CH}_{4} / \mathrm{kg}$ of milk from Holstein cows installed in respiration chambers. Enriquez-Hidalgo et al. (2014) reported $360 \mathrm{~g} / \mathrm{d}$ and $26.5 \mathrm{~g} / \mathrm{kg}$ of milk. Martin et al. (2008) obtained 418 $\mathrm{g} / \mathrm{d}$ and $17.4 \mathrm{~g} / \mathrm{kg}$ of milk from $\mathrm{SF}_{6}$ experiment. 
Moate et al. (2014) reported a $\mathrm{CH}_{4}$ intensity of 20.2 $\mathrm{g} / \mathrm{L}$ of milk.

More than only the similarities with $\mathrm{CH}_{4}$ estimates, the between and within lactation tendencies were also in agreement with the literature. The within lactation changes of daily PME (g/d) depicted in Figure 2 were similar to the one reported by Garnsworthy et al. (2012) using gas analyzer technique. Based on the reports of the same authors, the higher values of PME and the lower of PMI observed in second lactation were also expected and can be mainly explained by the changes of feed intake, feed efficiency, energy partitioning, and the evolution of milk production.

The MIR $\mathrm{CH}_{4}$ phenotypes should also have the expected behavior when they are compared with the evolution of MY. The curvilinear relationship between PMI and MY observed in this study (Figure 1b) suggested the same pattern between $\mathrm{CH}_{4}$ intensity and MY. This type of curve was also reported by Moate et al. (2014). Concerning PME, the correlation observed between these values and MY was equal to 0.33 , which was a very low value compared with the expected relationship and may be considered controversial. However, several elements that appear under closer scrutiny in our data can explain this value. First, there is no doubt that PME is related to the quantity of feed intake and there is no indication that this relationship differs significantly from a linear one. However, the relationship between the quantity of milk produced by the cow and its feed intake is not as linear and is also lactation stage dependent. Interestingly, Figure 1a shows that the pattern of the evolution of the relationship between PME and MY was not linear. Figure 7a represents the evolution between PME and MY also in regard to the evolution of DIM and the number of records as a function of classes of $1 \mathrm{~kg}$ of MY. By observing the pattern of this evolution more closely (Figure 7a) and limiting to MY classes with at least 1,500 test-day records (Figure $7 \mathrm{~b}), 2$ distinct areas appeared: one from 9 to $23 \mathrm{~kg}$ of milk/d and another from $24 \mathrm{~kg}$ to $38 \mathrm{~kg}$ of milk/d. The first area showed an almost linear increase of PME with MY and a strong positive correlation between them (0.83), and the second area showed first a stagnation of the increase of PME and then after $30 \mathrm{~kg} / \mathrm{d}$ a slight, almost linear, decrease of PME leading to a negative correlation $(-0.43)$. Under more close scrutiny, we can observe that the evolution of PME as a function of MY class in the first area (i.e., positive correlation) can be largely explained by the average DIM of each MY class $(\mathrm{R}=-0.95)$. Therefore, if DIM increased, PME decreased. This is expected due to the relationship between feed intake and DIM in late lactation, as all average DIM were $>170 \mathrm{~d}$. The second area (until 38 $\mathrm{kg} / \mathrm{d}$ to have a sufficient number of records to calculate the average PME; Figure 7b) was less explained by DIM and showed a positive relationship between PME and DIM (0.56). This is consistent with the fact that this area was more associated with cows in the first part ( $<165$ DIM) of their lactation, therefore increasing their feed intake and their PME with DIM. Moreover, 3 associated elements might be put forward to explain the behavior for high classes of MY. First, high-yielding cows might be more efficient, which leads to increasing MY without higher emissions of $\mathrm{CH}_{4}$. But we have no elements to prove this. Second, cows in early lactation produce more milk, but potentially reach their feed intake limits too, therefore mobilizing energy from their adipose tissue to produce additional milk, this milk being not related to an increase of PME. Third, in Belgium currently the feeding systems used increase the ratio of concentrates to roughage strongly for MY over $30 \mathrm{~kg}$, in many farms even for lower levels of production, because of the widespread use of concentrate feeding stations. These increasing levels of concentrates in the feeding of higher MY imply relatively lower $\mathrm{CH}_{4}$ emissions. Unfortunately, no data about feed intake or composition as well as feed efficiency are available in the Walloon region of Belgium to confirm all these hypotheses.

Even if the calibration coefficient of determination was almost equal to 1 , all of these results confirmed that the $\mathrm{MIR} \mathrm{CH}_{4}$ phenotypes (i.e., indirect $\mathrm{CH}_{4}$ proxy) had a behavior in line with the expectations based on the findings obtained from direct $\mathrm{CH}_{4}$ measurements or estimates.

\section{Heritability of MIR $\mathrm{CH}_{4}$ Traits}

Several recent studies described the genetic regulation of either $\mathrm{CH}_{4}$ emissions or proxies of $\mathrm{CH}_{4}$ emissions predicted from feed intake. The estimation of heritability from direct $\mathrm{CH}_{4}$ measurements on dairy cows using respiration chambers, considered as the gold standard method, is not feasible due to an insufficient acquisition of $\mathrm{CH}_{4}$ phenotypes for technical and financial reasons. Currently, the gas analyzer instrument allows a larger $\mathrm{CH}_{4}$ data acquisition. Various results of heritability were published in the literature: for instance, 0.05 by Pickering et al. (2015) and $0.21 \pm 0.06$ by Lassen and Løvendahl (2016). However, such studies were also conducted at relatively low scale even though the study of Lassen and Løvendahl covered 20 herds and 1,745 cows. To conduct larger scale studies, the use of $\mathrm{CH}_{4}$ proxies is interesting. A proxy is a trait directly or indirectly correlated with the interest trait. By using $\mathrm{MIR} \mathrm{CH}_{4}$ phenotypes, the current study enters in this context. Indeed, MIR $\mathrm{CH}_{4}$ phenotypes can be considered as indirect $\mathrm{CH}_{4}$ proxies. From more than 230,000 records 
and using random regression test-day models, this study found moderate heritability for PME, suggesting a moderate genetic component of the quantity of $\mathrm{CH}_{4}$ eructed by dairy cows. These results are in agreement with other studies conducted from $\mathrm{CH}_{4}$ direct measurements (e.g., Lassen and Løvendahl, 2016) and from $\mathrm{CH}_{4}$ proxies. Indeed, Kandel et al. (2015) found heritability ranged from 0.22 to 0.40 from $\mathrm{CH}_{4}$ proxies estimated from milk MIR FA based on equations developed by Chilliard et al. (2009). The heritability for $\mathrm{CH}_{4}$ proxies $(\mathrm{g} / \mathrm{d})$ derived from feed intake information was estimated to 0.13 by Pickering et al. (2015), 0.10 by Cassandro et al. (2010), and 0.35 by de Haas et al. (2011). Similarly, van Engelen et al. (2015) reported heritability of $\mathrm{CH}_{4}$ yield $(\mathrm{g} / \mathrm{kg}$ of DMI) predicted from several groups of FA. The heritability values ranged from 0.12 to 0.44 . Even if all of these studies were based on different methodologies, all support the existence of a genetic component of the enteric $\mathrm{CH}_{4}$ quantity eructed by dairy cows.

Moreover, the daily heritability tendencies within and between 2 lactations were also shown in this study. A slightly decrease of heritability was observed between the first and second lactation (0.25 vs. 0.22). Kandel et al. (2013) reported also this decrease using $\mathrm{MIR} \mathrm{CH}_{4}$ phenotypes predicted using an independent-lactationstage $\mathrm{MIR} \mathrm{CH}_{4}$ equation. However, the heritability values obtained by these authors were lower $(0.12,0.10$, and 0.09 from first, second, and third parity cows). These heritability differences could only be explained by the changes of the prediction equation because the studied cow population had the same origin. Within
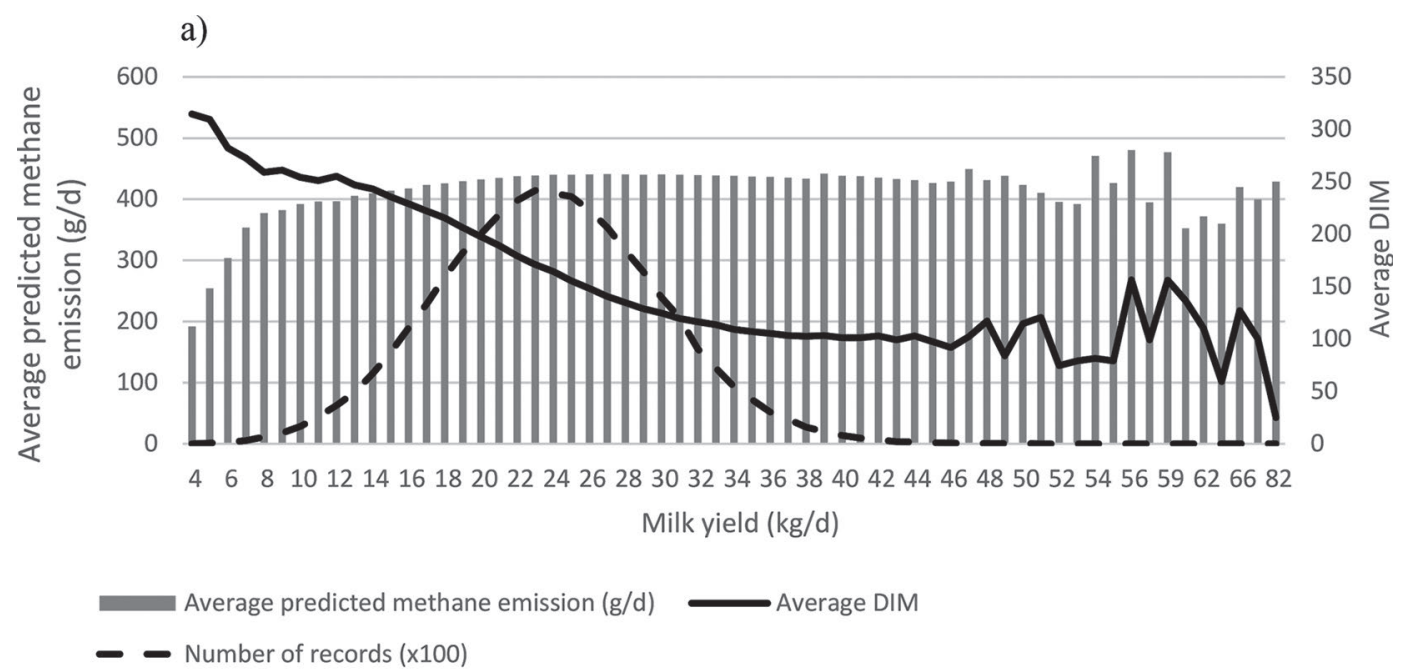

b)

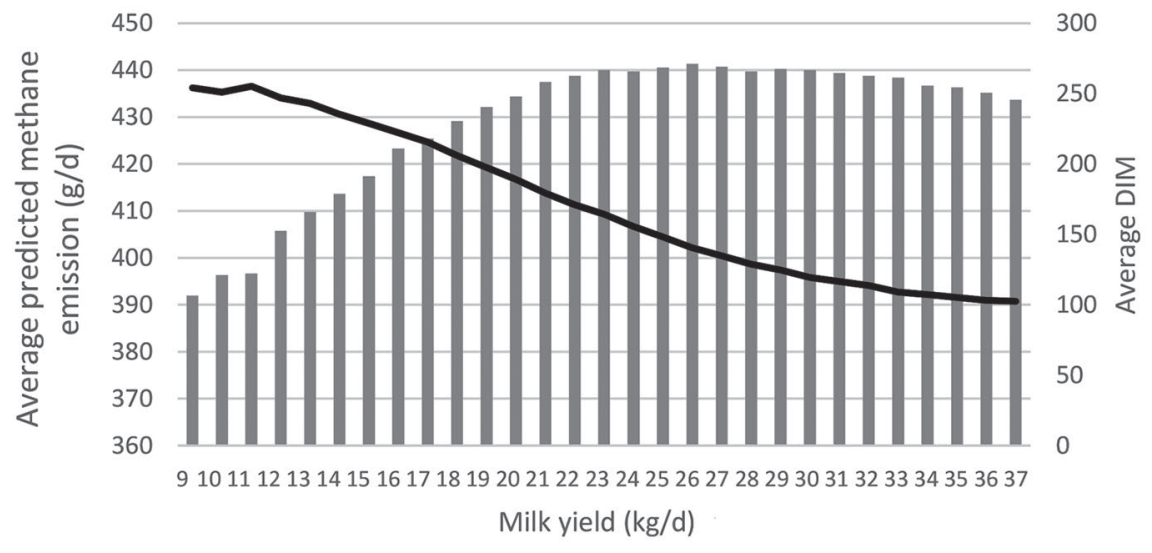

Average predicted methane emission $(\mathrm{g} / \mathrm{d}) \quad$ Average DIM

Figure 7. Evolution of predicted methane emission (g/d) and DIM in function of milk yield (g/d) from the entire first lactation data set (a) and from $\mathrm{CH}_{4}$ and DIM averages calculated from at least 1,500 test-day records (b). 
lactation evolution of $\mathrm{MIR} \mathrm{CH}_{4}$ phenotypes predicted using an independent-lactation-stage equation, as done by Kandel et al. (2013), did not have the expected shape (Vanlierde et al., 2015). In contrast, the use of a dependent-lactation-stage equation, as done in this study, allows the obtaining of MIR $\mathrm{CH}_{4}$ phenotypes, which have the expected DIM trend (Vanlierde et al., 2015). Within lactation differences in PME heritability curves from primiparous and second-parity cows were observed and could reflect differences in the partitioning of energy between first- and second-parity cows (Wathes et al., 2007).

We found that LMI was less heritable than PME (0.18 and 0.17; Table 2) and increased linearly throughout the lactation. These heritability values were similar to the ones observed for MY (0.16 and 0.14). Similar results were obtained by Lassen and Løvendahl (2016), who found $0.21 \pm 0.06$ for the $\mathrm{CH}_{4}$ intensity measured using the gas analyzer technique. de Haas et al. (2011) found a heritability of 0.58 using $\mathrm{CH}_{4}$ proxies based on feed intake information. However, the $\mathrm{CH}_{4}$ intensity trait was not log-transformed in those 2 studies.

\section{Genetic Variability of MIR $\mathrm{CH}_{4}$ Traits}

The calculated range of 305-d EBV for sires having daughters with $\mathrm{MIR} \mathrm{CH}_{4}$ phenotypes was equal to 22.15 and $29.41 \mathrm{~kg}$ in first and second lactation. These substantial EBV differences between sires were expected because of the obtained moderate heritability (Table 2) and the observed phenotypic variability of PME (Table 1). de Haas et al. (2011) reported a genetic standard deviation of approximately $6 \mathrm{~kg}$ of $\mathrm{CH}_{4}$ per lactation.

The high Spearman correlations values of sire EBV between first and second lactation for $\mathrm{MIR} \mathrm{CH}_{4}$ traits (0.92 for PME and 0.95 for LMI) suggested that the rankings of animal were similar between the 2 studied lactations.

\section{Phenotypic and Genetic Correlations Between MIR $\mathrm{CH}_{4}$ Traits and Milk Production Traits}

Negative phenotypic and genetic correlations were observed between PME and MY; genetic correlations were higher $(-0.07$ and -0.07 vs. -0.19 and -0.24 for first and second lactation, respectively; Table 2). These findings are surprising because older research reported a positive genetic correlation (de Haas et al., 2011; Kandel et al., 2013; Dong et al., 2015; Lassen and Løvendahl, 2016). As mentioned previously, the results obtained by Kandel et al. (2013) must be considered with caution due to the use of a dependent-lactationstage MIR $\mathrm{CH}_{4}$ equation. However, using gas analyzer technique, Lassen and Løvendahl (2016) also found a positive genetic correlation between $\mathrm{CH}_{4}$ emission $(\mathrm{g} / \mathrm{d}$ ) and fat- and protein-corrected milk $(0.42 \pm 0.10)$. The method of measurement for $\mathrm{CH}_{4}$ in grams per day used by these authors forced a positive correlation with MY. Indeed, the $\mathrm{CH}_{4}$ proxy was estimated by using the $\mathrm{CH}_{4}: \mathrm{CO}_{2}$ ratio multiplied by the daily $\mathrm{CO}_{2}$ emission and the heat-producing unit, which was calculated using the following formula: $\left(5.6 \times\right.$ live weight ${ }^{0.75}+22 \times$ fat- and protein-corrected milk $+1.6 \times 10^{-5} \times$ days carried calf). de Haas et al. (2011) found also a positive correlation (0.26) from feed-intake-based $\mathrm{CH}_{4}$ proxy; the very strong link between this proxy and DMI (0.99) could explain this correlation. Dong et al. (2015) mentioned that there was no apparent influence of genetic merit of cows. Phenotypically, the correlations observed in this study was close to 0 . This was expected based on the observed relationship between MY and PME (Figure 1a, 7a, and 7b). Indeed, because a mix of positive and negative relationships between MY and PME were present, phenotypic correlations of almost zero were expected. At the genetic level, the negative correlations between MY and PME were higher $(-0.19$ and -0.24 ; Table 2) but stayed relatively low. We have 2 remarks from these results. First, because the value was low, the MY information cannot be considered as a good proxy of $\mathrm{CH}_{4}$ at the genetic level. Second, if a breeding selection is conducted for high-producing cows, the PME will decrease slightly. Unfortunately, it is known that high-milk-producing cows tend to have more problems of fertility and longevity. This is not desired. Therefore, further studies must be conducted about the links between PME and the other traits included in the selection index, such as, for instance, fertility or longevity.

Based on the positive genetic correlations between MY and FY (0.79 and 0.84), it was expected to observe negative correlations between PME and FY, but the correlations were positive (0.11 and 0.12$)$. This can be explained. Soyeurt et al. (2008) showed that if MY increased, fat content decreased and UFA increased (Soyeurt et al., 2008). Based on the findings of van Lingen et al. (2014), this involved a decrease of $\mathrm{CH}_{4}$ emission $(\mathrm{g} / \mathrm{d})$. Indeed, those authors reported negative correlations between the concentrations of trans $6+7+8+9$ C18:1, trans-10+11 C18:1, cis-11 C18:1, cis-12 C18:1, cis-13 C18:1, trans- $16+$ cis $^{-1}{ }^{14} \mathrm{C} 18: 1$, and cis-9,12 C18:2 in milk fat and $\mathrm{CH}_{4}$ emission. Therefore, the slight positive correlation can be explained by the combination of fat dilution in higher milk production and the changes of milk fat composition in milk produced by high daily milk productive cows. The changes of genetic correlations within lactation were also expected because as mentioned previously $\mathrm{CH}_{4}$ is influenced by the changes of milk FA composition and these FA vary within lactation (Bastin et al., 2013). The phenotypic 
correlations between PME and FY were equal to 0, but the changes of correlation value throughout the lactation were important. For instance, in first lactation, negative correlations were observed until 120 DIM and then became positive.

The PY is more related to nitrogen efficiency than $\mathrm{CH}_{4}$ emissions but MY and PY were strongly positively genetically correlated (0.92 and 0.94; Table 2$)$. Therefore, the slight negative correlations between PME and PY $(-0.05$ and -0.04$)$ were expected. The same conclusion can be formulated at the phenotypic level.

The observed phenotypic and genetic correlations between LMI and production traits (MY, FY, and PY) were all highly negative for the 2 studied lactations (Table 2). Therefore, these results support the hypothesis that an increase of cow productivity (i.e., higher MY, FY, and PY) will lead to a decrease of $\mathrm{CH}_{4}$ intensity per $\mathrm{kg}$ of milk (Gerber et al., 2013). This relationship confirmed the suggestion of Wall et al. (2010) that the use of higher milk producing cows in a herd can be regarded as one of the mitigation options to reduce the environmental effect of the dairy production system. However, this approach could imply fertility and longevity, which could also affect the final calculation of carbon footprint of a specific herd. Future investigations must be conducted based on life cycle assessment to verify this.

\section{PME as Selection Trait}

Selection for $\mathrm{CH}_{4}$ mitigation has to be conceived inside adapted breeding programs using updated breeding objectives obtained with selection indexes also containing $\mathrm{CH}_{4}$ indicator traits. In this study, $2 \mathrm{CH}_{4}$ predictions were studied (PME and LMI). Both traits were heritable and presented a genetic variability on the studied dairy cattle. Compared with LMI, PME is a direct $\mathrm{CH}_{4}$ quantity trait. For all of these reasons, PME would be preferred for a future inclusion in a selection index. Moreover, the relationship between PME and LMI was genetically strong (0.71 and 0.72 in first and second lactation) suggesting to the inclusion of one of these traits will affect the other. Before inclusion of PME in a selection index, further studies must be conducted. Indeed, the relationship between PME and other traits of economic interest must to be known to avoid any undesired effect on cow health, longevity, and fertility as well as on milk production and composition.

\section{CONCLUSIONS}

In summary, due to their heritability and genetic variation, PME and LMI can be introduced in the selection index to consider the environmental effect of milk production in the future breeding objectives, but PME would be preferred as it is a direct $\mathrm{CH}_{4}$ quantity proxy. However, the genetic correlations between PME and LMI were high, suggesting that selection of one will trigger improvement of the other. The genetic regulation of PME and LMI differed between early and later lactation especially in first lactation. Different within lactation correlations suggested dynamic relationships between milk production traits and $\mathrm{CH}_{4}$ emissions. Before the introduction of PME in a selection index, further studies must be conducted to evaluate the effect of this inclusion in all traits already present in the current selection index and not only the common production traits as done in this study, notably because the results suggested that the use of cows with higher milk productivity can be a mitigation option but it is known that such cows have more problem of robustness, fertility, and longevity. Moreover, the improvement and the validation of MIR phenotypes must continue to ensure that the MIR $\mathrm{CH}_{4}$ proxy used is reliable and accurate.

\section{ACKNOWLEDGMENTS}

The authors acknowledge the support provided by the European Commission under the Seventh Framework Program for the GreenhouseMilk and GplusE projects, grant agreements FP7-PEOPLEITN-2008 238562 and FP7-KBBE-613689, the contribution of the COST Action FA1302 Methagene (http://www.methagene.eu), and the Public Service of the Walloon Region of Belgium (SPW-DGO3) through the Methamilk project. The content of the paper reflects only the view of the authors; the European Community is not liable for any use that may be made of the information contained in this publication. The authors acknowledge the Walloon Breeding Association (Ciney, Belgium) for providing the pedigree database, the Comite du Lait (Battice, Belgium) for supplying the MIR spectra, and University of Liège [SEGI (Service général d'informatique) facility, Gembloux, Belgium] for the use of the NIC3 and NIC4 supercomputers.

\section{REFERENCES}

Bastin, C., H. Soyeurt, and N. Gengler. 2013. Genetic parameters of milk production traits and fatty acid contents in milk for Holstein cows in parity 1-3. J. Anim. Breed. Genet. 130:118-127.

Cassandro, M., A. Cecchinato, M. Battagin, and M. Penasa. 2010. Genetic parameters of methane production in Holstein Friesian cows. In Proceeding of the 9th World Congress on Genetics Applied to Livestock Production (WCGALP), Leipzig, Germany. German Society for Animal Production, Bonn, Germany.

Chilliard, Y., C. Martin, J. Rouel, and M. Doreau. 2009. Milk fatty acids in dairy cows fed whole crude linseed, extruded linseed, or linseed oil, and their relationship with methane output. J. Dairy Sci. 92:5199-5211. 
de Haas, Y., J. J. Windig, M. P. L. Calus, J. Dijkstra, M. de Haan, A. Bannink, and R. F. Veerkamp. 2011. Genetic parameters for predicted methane production and potential for reducing enteric emissions through genomic selection. J. Dairy Sci. 94:6122-6134.

Dehareng, F., C. Delfosse, E. Froidmont, H. Soyeurt, C. Martin, N. Gengler, A. Vanlierde, and P. Dardenne. 2012. Potential use of milk mid-infrared spectra to predict individual methane emission of dairy cows. Animal 6:1694-1701.

Dijkstra, J., S. M. van Zijderveld, J. A. Apajalahti, A. Bannink, W. J. J. Gerrits, J. R. Newbold, H. B. Perdok, and H. Berends. 2011. Relationships between methane production and milk fatty acid profiles in dairy cattle. Anim. Feed Sci. Technol. 166:590-595.

Dong, L. F., T. Yan, C. P. Ferris, D. A. McDowell, and A. Gordon. 2015. Is there a relationship between genetic merit and enteric methane emission rate of lactating Holstein-Friesian dairy cows? Animal 9:1807-1812.

Enriquez-Hidalgo, D., T. Gilliland, M. H. Deighton, M. O'Donovan, and D. Hennessy. 2014. Milk production and enteric methane emissions by dairy cows grazing fertilized perennial ryegrass pasture with or without inclusion of white clover. J. Dairy Sci. 97:1400-1412.

Fischer, T. M., A. R. Gilmour, and J. H. J. van der Werf. 2004. Computing approximate standard errors for genetic parameters derived from random regression models fitted by average information REML. Genet. Sel. Evol. 36:363-369.

Garnsworthy, P. C., J. Craigon, J. H. Hernandez-Medrano, and N. Saunders. 2012. Variation among individual dairy cows in methane measurements made on farm during milking. J. Dairy Sci. 95:3181-3189.

Gerber, P. J., H. Steinfeld, B. Henderson, A. Mottet, C. Opio, J. Dijkman, A. Falcucci, and G. Tempio. 2013. Tackling climate change through livestock - A global assessment of emissions and mitigation opportunities. FAO, Rome, Italy.

Kandel, P. B., N. Gengler, and H. Soyeurt. 2015. Assessing variability of literature based methane indicators traits in a large dairy cow population. Biotechnol. Agron. Soc. Environ. 19:11-19.

Kandel, P. B., M.-L. Vanrobays, A. Vanlierde, F. Dehareng, E. Froidmont, P. Dardenne, E. Lewis, F. Buckley, M. H. Deighton, S. McParland, N. Gengler, and H. Soyeurt. 2013. Genetic parameters for methane emissions predicted from milk mid-infrared spectra in dairy cows. Page 279 in Proc. Adv. Anim. Biosci. (5th Greenhouse Gases Animal Agriculture Conference). Cambridge Journals, Cambridge, UK.

Lassen, J., and P. Løvendahl. 2016. Heritability estimates for enteric methane production in dairy cattle using non-invasive methods. J. Dairy Sci. 99:1959-1967.

Martin, C., J. Rouel, J. P. Jouany, M. Doreau, and Y. Chilliard. 2008. Methane output and diet digestibility in response to feeding dairy cows crude linseed, extruded linseed, or linseed oil. J. Anim. Sci. $86: 2642-2650$.

Misztal, I. 2012. BLUPF90 family of programs. Accessed Oct. 2013. http://nce.ads.uga.edu/wiki/doku.php?id=application_programs.

Moate, P. J., S. Richard, O. Williams, M. H. Deighton, J. E. Pryce, B. J. Hayes, J. L. Jacobs, R. J. Eckard, M. C. Hannah, and W. J. Wales. 2014. Mitigation of enteric methane emissions from the
Australian dairy industry. Pages 121-140 in Proc. 5th Australasian Dairy Symp., Hamilton, New Zealand. Australian Dairy Science Symposium, Narellan, Australia.

Pickering, N. K., M. G. G. Chagunda, G. Banos, R. Mrode, J. C. McEwan, and E. Wall. 2015. Genetic parameters for predicted methane production and laser methane detector measurements. J. Anim. Sci. 93:11-20.

Soyeurt, H., P. Dardenne, F. Dehareng, C. Bastin, and N. Gengler. 2008. Genetic parameters of saturated and monounsaturated fatty acid content and the ratio of saturated to unsaturated fatty acids in bovine milk. J. Dairy Sci. 91:3611-3626.

Soyeurt, H., F. Dehareng, N. Gengler, S. McParland, E. Wall, D. P. Berry, M. Coffey, and P. Dardenne. 2011. Mid-infrared prediction of bovine milk fatty acids across multiple breeds, production systems, and countries. J. Dairy Sci. 94:1657-1667.

van Engelen, S., H. Bovenhuis, J. Dijkstra, J. A. M. van Arendonk, and M. H. P. W. Visker. 2015. Genetic study of methane production predicted from milk fat composition in dairy cows. J. Dairy Sci. 98:8223-8226.

van Lingen, H. J., L. A. Crompton, W. H. Hendriks, C. K. Reynolds, and J. Dijkstra. 2014. Meta-analysis of relationships between enteric methane yield and milk fatty acid profile in dairy cattle. J. Dairy Sci. 97:7115-7132.

Vanlierde, A., M.-L. Vanrobays, F. Dehareng, E. Froidmont, H. Soyeurt, S. McParland, E. Lewis, M. H. Deighton, F. Grandl, M. Kreuzer, B. Gredler, P. Dardenne, and N. Gengler. 2015. Innovative lactation-stage-dependent prediction of methane emissions from milk mid-infrared spectra. J. Dairy Sci. 98:5740-5747.

Vanlierde, A., M.-L. Vanrobays, N. Gengler, P. Dardenne, E. Froidmont, H. Soyeurt, S. McParland, E. Lewis, M. H. Deighton, M. Mathot, F. Grandl, M. Kreuzer, B. Gredler, and F. Dehareng. 2016. Milk mid-infrared spectra enable prediction of lactationstage dependent methane emissions of dairy cattle within routine population-scale milk recording schemes. Anim. Prod. Sci. $56: 258-264$.

Veneman, J. B., S. Muetzel, K. J. Hart, C. L. Faulkner, J. M. Moorby, H. B. Perdok, and C. J. Newbold. 2015. Does dietary mitigation of enteric methane production affect rumen function and animal productivity in dairy cows? PLoS One 10:e0140282.

Wall, E., G. Simm, and D. Moran. 2010. Developing breeding schemes to assist mitigation of greenhouse gas emissions. Animal 4:366-376.

Wathes, D. C., N. Bourne, Z. Cheng, G. E. Mann, V. J. Taylor, and M. P. Coffey. 2007. Multiple correlation analyses of metabolic and endocrine profiles with fertility in primiparous and multiparous cows. J. Dairy Sci. 90:1310-1325.

Wollenberg, E., M. Richards, P. Smith, P. Havlik, M. Obersteiner, F. N. Tubiello, M. Herold, P. Gerber, S. Carter, A. Resinger, D. P. van Vuuren, A. Dickie, H. Neufeldt, B. O. Sander, R. Wassmann, R. Sommer, J. E. Amonette, A. Falcucci, M. Herrero, C. Opio, R. M. Roman-Cuesta, E. Stehfestn, H. Westhoek, I. Ortiz-Monasterio, T. Sapkota, M. C. Rufino, P. K. Thornton, L. Verchot, P. C. West, J.-F. Soussana, T. Baedeker, M. Sadler, S. Vermeulen, and B. M. Campbell. 2016. Reducing emissions from agriculture to meet $2^{\circ} \mathrm{C}$ target. Glob. Change Biol. 22:3859-3864. 